\title{
Building a Better World with Science and Technology: Curious Future Insight
}

\author{
Ulrich A. K. Betz
}

\section{Merck 350th anniversary science \& technology workstream}

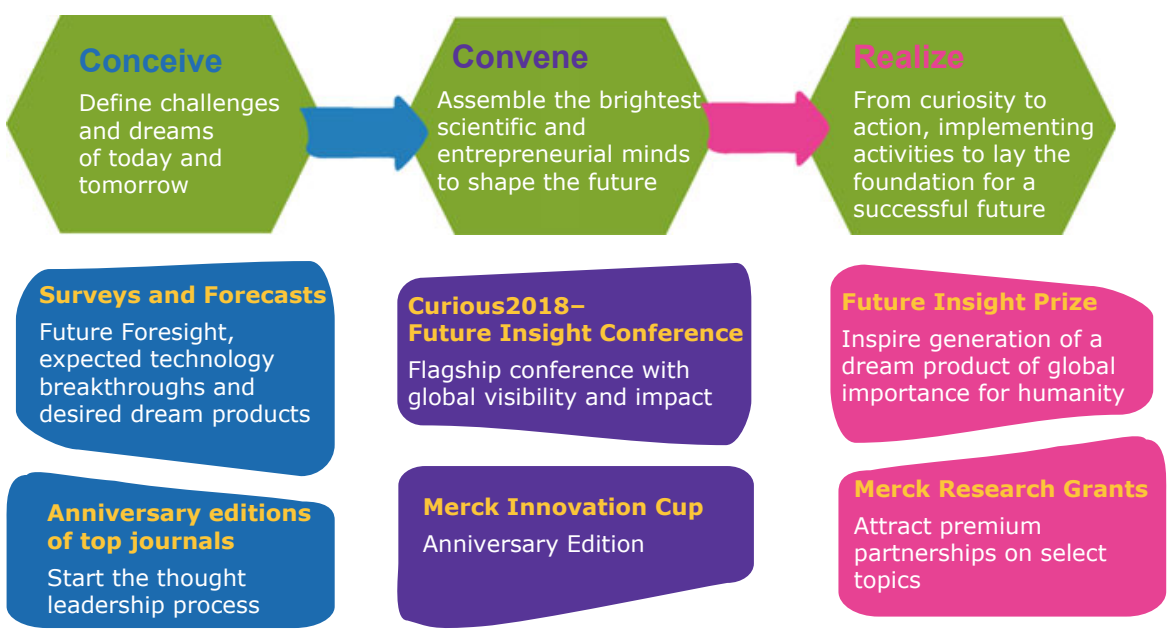

The original version of this chapter was inadvertently published as non-open access. It has now been changed to open access with the copyright holder name "The Author(s)". The correction to this chapter is available at [https://doi.org/10.1007/978-3-030-16061-6_18]

Electronic supplementary material The online version of this chapter (https://doi.org/10.1007/9783-030-16061-6_2) contains supplementary material, which is available to authorized users.

U. A. K. Betz ( $\bowtie)$

Vice President Innovation Merck,

Darmstadt, Germany

e-mail: ulrich.betz@merckgroup.com
When I was given the chance to lead the science and technology workstream of Merck's 350th anniversary, it was immediately clear that the overall theme of the activities should not be to primarily look back on what great things the company did in the past 350 years, but rather to look ahead and to help ensure a bright future for the organization if not for the next 350 but at least for the next 35 years. In addition to a clear future orientation, at the occasion of the 350th anniversary and being the world's oldest pharmaceutical and chemical company, the program should contain some major aspects going beyond 
boosting the company business but helping address key challenges of humanity and giving something back to the world at the occasion of this phenomenal birthday. And third, the highlight of the entire program should be a big science conference with global impact that brings together some of the world's best scientists and most accomplished entrepreneurs to explore the future of science and technology what then later materialized as the Curious2018-Future Insight Conference. The overall ambition of the science and technology workstream was summarized in the following mission statement: "Working with the best minds in science and entrepreneurship to realize the dreams of a better tomorrow!".

The program that was finally put together and endorsed by Merck management and the Merck owner family consisted of three consecutive phases.

The main goal of phase one, the conceive phase, was to start the thought leadership process and to define the challenges and dreams of today and tomorrow. Together with the journals Nature, Science/AAAS, Harvard Business Reviews and Technology Forecasting and Social Change, in total more than 2000 scientists and business leaders were surveyed. The results were published via Harvard Business Reviews Analytical Services (Breakthrough Innovation in the twentyfirst Century, https://hbr.org/sponsored/2018/03/ breakthrough-innovation-in-the-21st-century) and in Technology Forecasting and Social Change (in press 2019).

Contributing to this phase, additional papers were published such as a review summarizing technological progress in the past centuries combined with an outlook into the future (Is the force awakening? https://www.sciencedirect. com/science/article/pii/S0040162517309733/pdf ft?md5=cf000fcaf784353d1db25cc231e1e 944\& pid=1-s2.0-S0040162517309733-main.pdf) or a special Nature Outlook on the future of medicine (The future of medicine, https://www.nature. com/collections/zfnjwhjjct) as well as a special edition of Angewandte Chemie (https:// onlinelibrary.wiley.com/toc/15213773/2018/57/16) and a special Merck advertorial along with presentation of the Technology Breakthrough of the year 2017 in Science Magazine (Boldly imagining the next 350 years, http://www. sciencemag.org/advertorials/boldly-imaginingnext-350-years) and last but not least a review article about the Merck Innovation Cup that had run successfully for seven years (An innovators midsummer dream come true, http://www. europeanbusinessreview.com/an-innovatorsmidsummer-dream-come-true/).

Phase number 2, the convene phase, had the goal to assemble the brightest scientific and entrepreneurial minds to shape the future. It involved the flagship science conference Curious2018-Future Insight along with the Anniversary Edition of the Merck Innovation Cup. In total, about 1500 people were coming together at the occasion of these meetings.

Last but not least, the goal of phase 3, the realize phase, was to move from curiosity to action and to set in place the infrastructure, processes and resources to start implementing the best ideas and partnership proposals worked out during the two preceding phases and to initiate activities to lay the foundation for a successful future.

At the end of 2018, the 350th anniversary year, we can now look back at an extremely successful track record of the science and technology workstream, and the main key achievements are:

(1) Curious2018 - Future Insight Conference with $>60$ top speakers incl. six Nobel Laureates, 1300 participants, was established as top global scientific flagship conference on the future of science and technology.

(2) The Merck Future Insight Prize (http:// futureinsightprize.merckgroup.com http:// futureinsightprize.emdgroup.com) with impact for the next 35 years was rolled out pioneering the dream product concept.

(3) The Darmstadt Science Declaration-Make Science Not War (http://make-science-notwar.org) was rolled out and initiated a global movement to create a bright future with science and technology. 
(4) The Anniversary Innovation Cup (http:// innovationcup.merckgroup.com, http:// innovationcup.emdgroup.com) for young talent achieved an all-time high new record number of applications from all over the world 2200 and resulted in 15 innovative project ideas worked out, and 13 of these at the end of 2018 are being implemented.

(5) The 350th Anniversary Research Grants achieved the highest response ever from the scientific community in the history of Merck (with $>1300$ research project proposals incl. from elite universities such as Harvard or Stanford). Ten grants of up to more than 1 million $€$ each were awarded covering all Merck businesses (health care, life science, performance materials and digital).

(6) Ten publications in top journals such as Nature, Science, Harvard Business Reviews and Angewandte Chemie were published covering the 350th anniversary activities.

(7) Surveys with $>2000$ scientists and business leaders on future game changers were performed.

(8) Two international business awards (Stevie Gold Awards) were won: Manager of the Year, Innovator of the Year.

As stated before, the Curious2018-Future Insight Conference was the crown jewel and flagship of the entire 350th anniversary science and technology workstream. Together with a team of Merck internal and external scientists and managers, a series of key paradigms for the conference were agreed. First of all, the key goal was to assemble the best scientists and most accomplished entrepreneurs from all over the world based on top achievements and with a high chance to further shape the progress of science and technology in the future. The conference should explore the future of science and technology with a timeframe of 35 years ahead. A broad range of topics should be covered, largely inspired by Merck's business areas. In the field "Healthy Lives - new breakthrough therapies and diagnostics," scientific topics around pathophysiological mechanisms, disease biology, new breakthrough drugs and diagnostics should be elucidated. The field "Live reimagined synthetic biology and beyond" should look at topics such as synthetic biology, gene editing and the biological revolution ahead. The area "Materials \& solutions - chemistry and more" should mainly focus on new innovative materials and their applications. The field of "Digitalization - the power of in silico" should cover the most disruptive game changer currently talked about, and last but not least the field of "Bright future - new ways of working together" should provide space for speakers covering topics on how an ideal innovator organization should look like, deal with new open innovation approaches up to completely new areas of science and the further development of society. Within all activities, we wanted to clearly focus on a bright future, a utopian not a dystopian view and on the power science and technology can exert to create a bright future. This positive and utopian outlook, the ambition to connect people from all over the planet with this unifying mission statement of building a better world and a bright future with the help of science and technology, was more or less the red threat for all our activities, and it even manifested itself in the key visual that was chosen for the conference, the bright supernova spreading its light into the darkness of space!

Rather than just providing a compilation of lectures, we wanted the conference to also comprise interactive modules and to provide ample time and space for networking and discussions. In the end, the following modules were implemented:

\section{(1) Plenary keynote lecture}

These were the absolute highlights of the conference. $45 \mathrm{~min}$ (incl. Q\&A) speaking slots in front of all attendees $(\sim 1300)$. Usually, such speaker slots were only given to Nobel Laureates or other famous top scientist such as the genome pioneer Craig Venter or the CRISPR researcher Emmanuelle Charpentier. Speaking slots were given by invitation only. 
(2) Keynote lecture

These were speaking slots of the same length, but distributed over three parallel workstreams. Speaking slots were given by invitation only.

(3) Barcamp sessions

This innovative module provided speaking slots of 10 min length and was open for application.

(4) E-Poster sessions

Electronic posters display sessions around the conference's main topic fields, and also these slots were open for application.

(5) Exhibition

Exhibition booths could be booked/ purchased.

(6) AI-workshop

Together with the Fraunhofer Institute for Intelligent Analysis and Information Systems and the Fraunhofer Institute for Applied Information Technology, three interactive workshops were run around the topic of artificial intelligence.

(7) Partnering Meetings

Dedicated partnering meetings were organized with each keynote speaker and panelist of Curious2018 together with Merck scientists and managers in order to explore potential collaboration opportunities.

(8) Evening events

Two different evening events were organized comprising ample networking opportunities as well as exhibition of top innovative technologies and gadgets.

(9) Curiosity circle

The curiosity circle was comprised of a round theater seating setup and was mainly used for so-called ask-me-all sessions where keynote speakers made themselves available to answer general questions going beyond topics covered in their keynote lecture.

A three-day duration of the event was considered optimal with a start in the afternoon of day 1 allowing for travel to the location in the morning, a full-day program at day 2 and an afternoon end at day 3 to facilitate travel arrangements back home.
The most important prerequisite to create a top conference was to motivate top keynote speakers to come. First invitations for keynotes were already sent out in December 2017. For that purpose, an invitation card with an embedded screen playing a video was distributed. The second wave then consisted of a printed paper invitation card with special Merck pigment. With only a single exception, all keynote speakers were not paid a speakers fee but full coverage of business travel and accommodation was provided. In that regard, it was of utmost importance that Curious2018-Future Insight was an independent science conference sponsored by Merck at the occasion of its 350th anniversary, but not in a strict sense a corporate event!

The well-being of keynote speakers was always a key priority for the entire organization committee. This involved full reimbursement of all travel and accommodation costs as well as booking of pickups and transfers for airport and conference transportation. In addition, each keynote speaker was allocated a personal caretaker. Caretakers were Merck scientists that were available to accommodate the keynote speaker at all times and were available not only for all help and support required but also acted as personal capable guides for the conference including being able to conduct stimulating scientific discussions with the guests and making contact to other key guests of interest. All caretakers were volunteers from the company and were trained in multiple sessions prior to the event.

In addition to top keynote speakers also having capable moderators was a key success criterion for Curious2018.

The full conference program is attached as an appendix to this chapter.

The conference was also supported by a welcome address from the Germany Federal Minister of Education and Research, Anja Karliczek, with the following letter message read at the Curious2018-Future Insight Conference:

Life is full of challenges and opportunities. For centuries, science and research have been producing new developments to make the world a better place. Experience has shown that innovations are generated exactly where people from 
different disciplines, companies, institutions and countries come together and exchange ideas and knowledge. This diversity can also be found at Merck where an international team is continuously trying new paths - whether by using intelligent materials to improve electronic equipment, monitoring the quality of food and medicines, exploring the possibilities of genetic engineering or treating cancer. Merck's 350 years of work are proof of the good performance of German companies in the field of research and development. I wish all the participants a successful 2018 conference with inspiring discussions and the possibility to further enhance international cooperation.

The event was also supported by an event app that allowed participants to communicate and network. The app also provided an overview of the agenda, location and special events as well as organizational messaging.

Key for the success of the conference and its image as an independent science conference were clearly also the partnerships with Nature and AAAS/Science that both organized a panel discussion at the Curious2018-Future Insight Conference. The roundtable discussion done together with AAAS/Science revolved around the Technology Breakthrough of the year that is annually elected by Science. Topics covered were: CRISPR/synthetic biology, artificial intelligence, material sciences, astrobiology and solar system exploration. The roundtable organized together with Nature was an extension of the Nature Outlook published earlier in the year and focused on the Future of Medicine, covering new therapeutic modalities such as the microbiome, personalized medicine and biomarkers as well as big data, AI and machine learning.

For operational excellence and top logistics, the collaboration with the event management agency VOK DAMS was of key importance. The project team of Merck and VOK DAMS met weekly for more than 1.5 years to prepare the event.

All tickets for Curious2018-Future Insight were given out for free, around one half via a direct invitation and the other half after an application process. Overall $50 \%$ of attendees had an academic background from around 150 different institutions, $50 \%$ were from a corporate background, and $40 \%$ of attendees were female.
Regional distribution was $78 \%$ from Europe, $16 \%$ from America, 5\% from Asia and 1\% from Africa/Middle East.

The speakers panel consisted of more than 60 top speakers and panelists from all over the world, including six Nobel Laureates: Frances H. Arnold, Nobel Prize in Chemistry 2018; Fraser Stoddart, Nobel Prize in Chemistry 2016; Jean-Marie Lehn, Nobel Prize in Chemistry 1987; Joachim Frank, Nobel Prize in Chemistry 2017; Bruce Beutler, Nobel Prize in Physiology or Medicine 2011; Harald zur Hausen, Nobel Prize in Physiology or Medicine 2008. Frances Arnold has actually been allocated the Nobel Prize in 2018 a few weeks after speaking at the conference!

Another key highlight of the event was the rollout of the Future Insight Prize (http:// futureinsightprize.merckgroup.com and http:// futureinsightprize.emdgroup.com), by the CEO of Merck Stefan Oschmann at day 2 of the conference. The Future Insight Prize was initiated and designed by Ulrich Betz and will be awarded annually from 2019 onwards to honor and enable outstanding achievements in science and technology toward a groundbreaking innovation, enabling the later realization of a dream product, important for the future of humanity in the areas of health, nutrition and energy with a research grant of up to 1 million $€$ sponsored by Merck. The Future Insight Prize is covered in detail in the following chapter of this book. The prize will be given out for the first time in 2019 for work enabling the later realization of the dream product Pandemic Protector, to protect humanity from the outbreak of a new viral pandemic. In the following years Future Insight Prizes will be given out on the topics of antibiotic resistance, food generation and clean energy.

Already at day 1 of the conference, the Darmstadt Science Declaration was rolled out. The Darmstadt Science Declaration is a global call to action to devote more resources to the advancement of science and technology with the task to enable humanity to solve the challenges of today and to realize the dreams of a better tomorrow. Everybody is cordially invited to sign this declaration at http://darmstadt-science- 
declaration.org). The call was later also given the subline "Make Science not War." Further details are described in an article in Angewandte Chemie (https://onlinelibrary.wiley.com/doi/full/10. 1002/anie.201811929).

The Darmstadt Science Declaration reads in detail:

We, the signatories, are people of different national origins, creeds and convictions. We all firmly believe that human progress is deeply linked to further advances in science and technology. We are truly convinced that science is a force for good which enables us to solve many of mankind's most pressing challenges. We believe that huge opportunities will arise from future science and technology efforts. Yet we are also very well aware of the responsibility and accountability we bear for the new technologies that are realized. We call on all nations, societies and organizations to devote more resources to the advancement of science and technology. We encourage the international community to join forces in battling debilitating diseases, ensuring sufficient food for a growing world population, stopping the destruction of our environment, and engaging in joint endeavors to elucidate the secrets this fascinating universe holds. Nothing shall be impossible.

The Curious2018-Future Insight Conference has received enthusiastic feedback. A participants' survey resulted in $98 \%$ of participants agreeing that the event has increased Merck's reputation as leading science and technology company. $97 \%$ of all participants rated the overall experience of the conference as excellent or very good. In terms of the most important conference topic, $36 \%$ voted for healthy livesnew breakthrough therapies and diagnostics, $19 \%$ for live reimagined-synthetic biology and more, $19 \%$ for bright future-new ways of working together, $15 \%$ for materials and solutions - chemistry and beyond and $12 \%$ for digitalization - the power of in silico.

The following participants' statements that were shared via the survey give a good impression on the spirit of the event:

I will never see such a line-up of speakers anymore in my entire life

This was the Woodstock of science.

It will leave a lasting legacy.

The quality of the program was outstanding.
Impressive inspiring scientific community and talks. Perfect organization and ideal venue One of the best Conferences I have ever participated! Should become an annual event Probably the next step up in quality is the Nobel Price Ceremony!

This conference has shown the world, this 350 years old company has recharged with the future inspiration and driven with curiosity for future success.

The speaker line-up was unbelievable.

Of the impact that goes beyond the conference: the Darmstadt science declaration, the future insight prize, the plan to do the conference ongoing.

It is a groundbreaking conference making you feel the love, excitement and potential of science and technology everywhere!

Amazing talks. Never visited a comparable conference.

This was the best conference I have ever attended. Congrats to you and your team for organizing such an amazing, star-packed, thought-provoking and landmark event in history.

I am seriously thrilled that the event went so well. The feedback has been incredible.

You were a superstar at Curious2018.

A once in a lifetime event.

This was the best organized conference I have ever attended.

The best event I have ever attended.

Grandios event, perfectly organized, huge impact, congratulations.

Curious2018 was brilliantly designed and executed.

Very impressive in all aspects.

Thank you for the most amazing conference I have attended in recent times. As a recap I have written a poem to summarize.

I am at a lot of conferences and I can say that this was by far the most interesting, energetic and diverse I have witnessed in a long time.

What a stimulating event, it was truly fantastic.

You did an amazing job, I think everyone will remember it for another 350 years.

Truly a marvelous event. Thanks to Merck, Uli Betz and the entire team.

Congratulations on both the Curious2018 and the Innovation Cup. They both were absolutely first class all the way, brilliantly planned and executed. The Merck team should be so proud of the event against so many metrics - not just logistical, but as a pivotal boost to the culture of multi-disciplinary collaboration and long term human-centered scientific endeavor, which I personally think marks Merck out as a very special organization, and very different in mindset to other big pharmas.

Thank you Uli, it was a great conference and lots of fun. 
You hosted an amazing event in Darmstadt.

You and your colleagues deserve to be lauded and praised for your service to science. Please keep up the good work.

To mobilize such a large number of high quality on such international base I have not seen yet in my career, excellent job.

A conference of the highest standards.

The Curious2018 conference paired with the innovation cup were easily the most stimulating and exciting experiences of my scientific career thus far. I really cannot thank you enough.

Such days let us hope for the world and also for Germany.

It was indeed the most unique event I have attended in my 20 years on the circuit.

I had a great time there, such an incredibly well organized meeting!

Congratulations to you Dr. Betz for organizing an event of such epic proportions. It was definitely one of the best experiences of my life.

It was truly an amazing experience and one that I will always remember

Beyond official surveys, the feedback gathered in one-on-one discussions from participants directly was outstandingly positive too. People were enthusiastic, inspired by the positive outlook into the future, by the great science presented, the presence of so many people that had provided outstanding contributions to the advancement of science and technology and by the enthusiasm of all attendees. My personal experience from Curious2018-Future Insight was incredible. Never before in my live have I been approached by and received congratulations from so many amazing people. To see the top presenters on stage, the high-quality science, the stimulating discussions during the breaks and at the evening events, the top performance and enthusiasm of my team as well as the enthusiastic feedback was just phenomenal, it was a once-in-a-lifetime experience that I will certainly cherish for the rest of my life.

The conference together with the associated Future Insight Prize has received considerable echo in the media including TV, radio, print and social. Also Nature magazine has published a summary: https://www.nature.com/articles/ d42473-018-00168-z.

In addition, most of the presentations given at Curious2018 were videotaped and are available in a media library: https://curious2018.com/ media-library/.

Directly following the Curious2018-Future Insight Conference the Anniversary Edition of the Merck Innovation Cup (http://innovationcup. merckgroup.com and http://innovationcup. emdgroup.com) was conducted, and 15 teams consisting of 5-6 top graduate students plus one coach (alumni of previous editions of the Innovation Cup) were working over a week to come up with new ideas for innovative products solving key unmet challenges of humanity. The topics covered were the same as during the conference, and three teams each were working on healthy lives, live reimagined, materials and solutions, digitalization and bright future. Students received lectures and coaching from experienced professionals and retirees in a meeting of the generations. Teams presented their project plan at the last day of the Innovation Cup in front of a jury consisting of Merck researchers, managers and Merck-external experts, delegates from venture funds and accelerators as well as academic scientists. The presentation in front of the jury is considered a publication, and all worked-out ideas and project plans are released in the public domain for implementation. The winning team was awarded the Merck Innovation Cup along with 20,000 Euro for a project idea on synthetic biology: "Plastics to Biologics," involving a concept to turn plastics into biologics using engineered E. coli to produce methionine from PET.

As the Curious2018-Future Insight Conference was so successful, it will from now on be conducted bi-annually as an independent science conference, and the next event will take place in Darmstadt on July 13-15, 2020. Innovationdriven organizations from all over the world are invited to partner and join the initiative. Invited partners are: corporations, NGOs, scientific organizations, philanthropists and in general all interested individuals.

We have the ambition to grow the conference into the world's most renowned gathering on the future of science and technology covering a broad range of topics such as health care, drug 
discovery, synthetic biology, nutrition, material sciences, digitalization, mobility, energy, human mind and bright future - new ways of working together, it will be the "Davos" of science and technology.

Curious2018-Future Insight is bringing the world's best scientists and most accomplished entrepreneurs together to explore the future of science and technology, to solve the challenges of today and to enable the dreams for a better tomorrow, creating a bright future for humanity. You are invited to be a part of it.

Open Access This chapter is licensed under the terms of the Creative Commons Attribution-NonCommercial 4.0 International License (http://creativecommons.org/ licenses/by-nc/4.0/), which permits any noncommercial use, sharing, adaptation, distribution and reproduction in any medium or format, as long as you give appropriate credit to the original author(s) and the source, provide a link to the Creative Commons license and indicate if changes were made.
Acknowledgements Special thanks go to Stefan Oschmann, the Merck board and the Merck ownership family that have made the budget available to run this outstanding event. The Curious2018-Future Insight organization team consisted of: Beate Moch, Brendan Monks, Brigitte Alexander, Heike Schwarz-Schlenger, Ines Kahlert, Katharina Lenz, Kathrin Hackenberg, Kerstin Weber, Lea Flöring, Maike Kober, Melanie Heumann, Sarah Knick, Seline Wagner, Sonja Hatz, Tamara Engels, Timm Wutzler, Ulrich Betz plus many others that contributed substantially to the success of this endeavor.

The images or other third party material in this chapter are included in the chapter's Creative Commons license, unless indicated otherwise in a credit line to the material. If material is not included in the chapter's Creative Commons license and your intended use is not permitted by statutory regulation or exceeds the permitted use, you will need to obtain permission directly from the copyright holder. 